\title{
ReVIeW
}

\section{mTORC1 signaling in hepatic lipid metabolism}

\author{
Jinbo Han, Yiguo Wang ${ }^{\bowtie}$ \\ MOE Key Laboratory of Bioinformatics, Tsinghua-Peking Center for Life Sciences, School of Life Sciences, \\ Tsinghua University, Beijing 100084, China \\ $\triangle$ Correspondence: wangyiguo@biomed.tsinghua.edu.cn (Y. Wang) \\ Received March 2, 2017 Accepted April 4, 2017
}

\begin{abstract}
The mechanistic target of rapamycin (mTOR) signaling pathway regulates many metabolic and physiological processes in different organs or tissues. Dysregulation of mTOR signaling has been implicated in many human diseases including obesity, diabetes, cancer, fatty liver diseases, and neuronal disorders. Here we review recent progress in understanding how mTORC1 (mTOR complex 1) signaling regulates lipid metabolism in the liver.
\end{abstract}

KEYWORDS mTOR, mTORC1, lipogenesis, lipophagy

\section{INTRODUCTION}

Most organisms have evolved mechanisms to respond to dynamic environmental cues including nutrients, growth factors, and cellular energy levels for survival and growth. Mechanistic target of rapamycin (mTOR) integrates these environmental cues to modulate metabolic pathways for cell growth. Dysregulation of mTOR signaling has been implicated in many human diseases, including obesity, diabetes, cancer, and neuronal disorders (Cornu et al., 2013; Saxton and Sabatini, 2017).

TOR was identified in yeast genetic screens as the factor that confers resistance to the anti-fungal and immune depressant drug rapamycin, and its mammalian counterparts were identified shortly afterwards (Heitman et al., 1991; Cafferkey et al., 1993; Kunz et al., 1993; Brown et al., 1994; Sabatini et al., 1994; Sabers et al., 1995). mTOR is an evolutionarily conserved serine/threonine kinase that belongs to the phosphoinositide 3-kinase (PI3K)-related kinase family and exists in two distinct signaling complexes, mTOR complex 1 (mTORC1) and mTORC2 (Cornu et al., 2013; Saxton and Sabatini, 2017). Both mTORC1 and mTORC2 share four protein components, including the TOR kinase, DEP domaincontaining mTOR-interacting protein (DEPTOR) and mammalian lethal with Sec13 protein 8 (mLST8) (Cornu et al.,
2013; Saxton and Sabatini, 2017) (Fig. 1A). In contrast, regulatory-associated protein of mTOR (RAPTOR) and prolinerich AKT substrate $40 \mathrm{kDa}$ (PRAS40) are specific to mTORC1, while rapamycin-insensitive companion of mTOR (RICTOR), mammalian stress-activated protein kinase-interacting protein (mSIN1), and protein observed with RICTOR-1 and -2 (PROTOR1/2) are only associated with mTORC2 (Cornu et al., 2013; Saxton and Sabatini, 2017).

mTORC1 is sensitive to rapamycin and promotes protein synthesis and lipid synthesis, as well as inhibiting autophagy and lysosome biogenesis in response to growth factors, amino acids, stress, oxygen levels, and energy status. These responses occur in part through the phosphorylation of mTORC1 substrates, including ribosomal S6 kinase 1 (S6K1), eukaryotic translation initiation factor 4E (elF4E)-binding proteins 1 and 2 (4E-BP1/2), UNC-5 like autophagy activating kinase (ULK1), and transcription factor EB (TFEB) (Cornu et al., 2013; Lamming and Sabatini, 2013; Settembre et al., 2013b; Caron et al., 2015; Kim and Guan, 2015; Saxton and Sabatini, 2017). Growth factors such as insulin stimulate mTORC1 through the PI3K/AKT pathway. Activated AKT phosphorylates tuberous sclerosis complex 2 (TSC2) to inhibit TSC1, a GTPase-activating protein (GAP) for the small GTPase Ras homologue enriched in brain (RHEB), while the active RHEB strongly enhances mTOR activity (Inoki et al., 2002; Manning et al., 2002; Potter et al., 2002; Inoki et al., 2003a; Saucedo et al., 2003; Stocker et al., 2003; Tee et al., 2003; Zhang et al., 2003). Amino acids activate mTORC1 through the RAS-related GTP-binding protein (RAG) family of small GTPases, which promote the translocation of $\mathrm{mTORC} 1$ from the cytoplasm to the surface of lysosomes, where mTORC1 is activated by RHEB (Kim et al., 2008; Sancak et al., 2008; Sancak et al., 2010; Cornu et al., 2013; Saxton and Sabatini, 2017). Intracellular energy levels also regulate $\mathrm{mTORC} 1$ activity via TSC or RAPTOR in response to AMP-activated protein kinase (AMPK), or via the RAG GTPases in an AMPK-independent manner (Inoki et al., 2003b; Shaw et al., 2004; Gwinn et al., 2008; Kalender et al., 2010; Efeyan et al., 2013). 
A

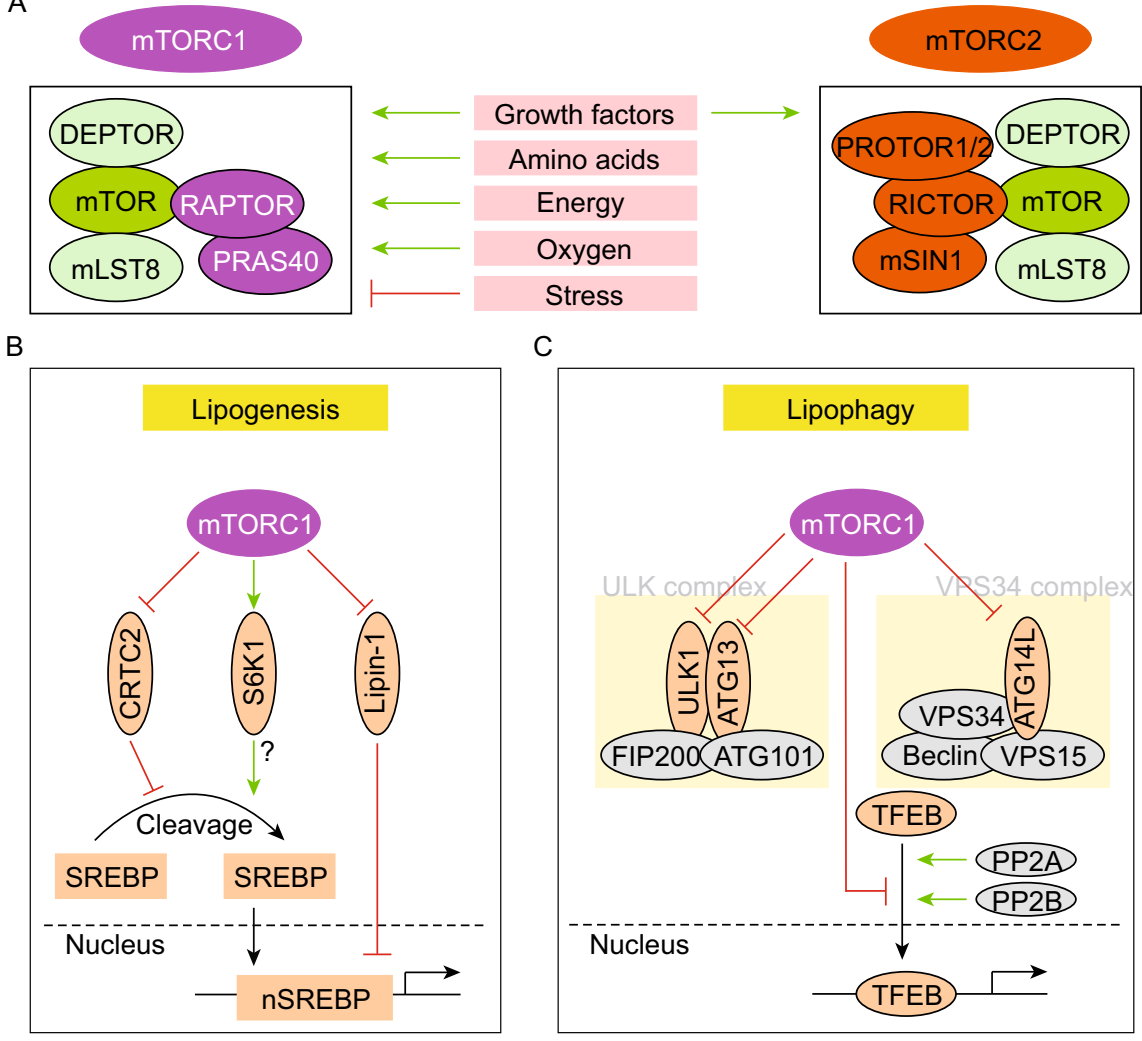

Figure 1. mTOR signaling in hepatic lipid metabolism. (A) The protein composition and key features of mTORC1 and mTORC2. mTORC1 responds to growth factors, amino acids, stress, oxygen and energy, while mTORC2 only responds to growth factors. (B) mTORC1 promotes SREBP-dependent lipogenesis through the phosphorylation of CRTC2, S6K1, and Lipin-1. (C) mTORC1 inhibits lipophagy by blocking autophagy initiation and attenuating lysosome biogenesis.

In contrast, mTORC2, which is insensitive to acute treatment with rapamycin but can be disrupted by chronic rapamycin treatment, responds to growth factors to modulate metabolism and cytoskeletal organization by activating AGC family kinases, including AKT, SGK1, and PKCa (Cornu et al., 2013; Saxton and Sabatini, 2017). mTORC2 phosphorylates AKT at Serine 473 in response to growth factor signaling and thereby enhances mTORC1 activity (Sarbassov et al., 2005; Cornu et al., 2013; Saxton and Sabatini, 2017). In addition, mTORC1 negatively regulates mTORC2 activity via phosphorylation of IRS1, Grb10, and mSIN1 (Harrington et al., 2004; Shah et al., 2004; Hsu et al., 2011; Yu et al., 2011; Cornu et al., 2013; Liu et al., 2013; Saxton and Sabatini, 2017). Although mTORC2 also regulates lipid homeostasis, much less is known about the substrates of mTORC2 than of mTORC1. Moreover, mTOR signaling regulates many metabolic and physiological processes, including protein synthesis, nucleotide synthesis, glucose metabolism, and lipid metabolism (Cornu et al., 2013; Caron et al., 2015; Saxton and Sabatini, 2017). In this review we focus on recent findings about the signaling mechanisms downstream of $\mathrm{mTORC} 1$ that regulate lipid metabolism in the liver.

\section{LIPID METABOLISM IN THE LIVER}

As a major site of lipogenesis and lipid oxidation, the liver is a central organ in lipid metabolism, while impaired hepatic lipid metabolism is tightly correlated with obesity, diabetes, and fatty liver disease (Samuel and Shulman, 2012; Rui, 2014). In the fed state, when carbohydrates are abundant, the liver converts glucose into fatty acids (FAs) by de novo lipogenesis (Rui, 2014; Wang et al., 2015). Depending on the metabolic status, hepatocytes also obtain FAs from lysosomes by autophagy, and can also take up FAs from the bloodstream, which are released from adipose tissue and digested food in the gastrointestinal tract. FAs are then processed to triacylglycerols (TAGs) and cholesterol esters for storage during feeding or metabolized to produce energy during fasting (Rui, 2014; Wang et al., 2015).

Hepatic lipogenesis includes de novo lipogenesis of FAs from acetyl-CoA or malonyl-CoA and further processing to TAGs. Lipogenesis is catalyzed by the rate-limiting enzymes acetyl-CoA carboxylase (ACC) and fatty acid synthase (FAS), both of which are transcriptionally controlled by various transcriptional regulators in response to nutrients and hormones, including sterol response element-binding protein (SREBP) family members, carbohydrate-responsive element 
binding protein (ChREBP), and nuclear receptors (PPARy, FXR, and LXR) (Rui, 2014; Wang et al., 2015). Insulin is the primary hormone that drives hepatic lipogenesis, while $\mathrm{PI} 3 \mathrm{~K} / \mathrm{AKT}$ signaling is required for both inhibition of gluconeogenesis and stimulation of lipogenesis (Rui, 2014; Wang et al., 2015). However, it is paradoxical that both gluconeogenesis and lipogenesis are enhanced in obese and/or diabetic models, suggesting that lipogenesis is selectively resistant to insulin. The results from Brown and Goldstein's lab show that inhibition of $\mathrm{mTORC} 1$ by rapamycin in primary rat hepatocytes and in rat liver tissues blocks insulin-stimulated lipogenesis, but has no effect on insulin-inhibited gluconeogenesis, indicating that $\mathrm{mTORC} 1$ is the point at which the insulin signaling pathway bifurcates to promote lipogenesis and inhibit gluconeogenesis (Li et al., 2010).

During fasting, glycogenolysis and gluconeogenesis are sequentially induced to produce glucose. Fasting also promotes lipolysis in adipose tissue, resulting in release of nonesterified fatty acids which are converted into ketone bodies in the liver through $\beta$-oxidation and ketogenesis (Rui, 2014; Wang et al., 2015). Autophagy is a conserved catabolic process that removes damaged macromolecules and organelles in response to stress and scarcity of nutrients (Rabinowitz and White, 2010; Mizushima and Komatsu, 2011). Recent studies have demonstrated that autophagy plays a critical role in lipid oxidation by shuttling lipid droplets to the lysosome for hydrolysis, a process named lipophagy (Singh et al., 2009; Rabinowitz and White, 2010; Mizushima and Komatsu, 2011).

\section{MTORC1 PROMOTES LIPOGENESIS}

mTORC1 plays a critical role in promoting lipogenesis by regulating the expression of many lipogenic genes. One important family of transcription factors that controls lipid synthesis is the SREBPs. SREBPs belong to the family of basic helix-loop-helix-leucine zipper (bHLH-Zip) transcription factors. The SREBP family consists of three closely related members, SREBP1a, SREBP1c and SREBP2, among which SREBP1C and SREBP2 are the major isoforms expressed in the liver (Horton et al., 2002; Goldstein et al., 2006; Ferre and Foufelle, 2007). SREBP1 is a master transcriptional regulator of insulin-stimulated fatty acid synthesis, whereas SREBP2 mainly controls cholesterol synthesis (Horton et al., 2002; Goldstein et al., 2006; Ferre and Foufelle, 2007). SREBPs reside in the endoplasmic reticulum (ER) as inactive precursors with a complex including the sterol cleavage activating protein (SCAP) and insulin-induced gene (INSIG). Upon sensing insulin stimulation or sterol depletion, the SREBP/SCAP complex disassociates from INSIG and binds to Sec24, a subunit of the COPII complex, and then buds from the ER. The $\mathrm{N}$-terminus of SREBP (nSREBP), which is released after cleavage by site-1 protease (S1P) and S2P in the Golgi, shuttles to the nucleus and induces the expression of genes involved in cholesterol and fatty acid synthesis (Horton et al., 2002; Goldstein et al., 2006; Ferre and Foufelle, 2007).

mTORC1 promotes the trafficking, processing, and transcription of SREBPs (Fig. 1B). In 2008, Portsmann and colleagues were the first to show that rapamycin impairs the nuclear accumulation of SREBPs and downregulates the expression of lipogenic genes (Porstmann et al., 2008). The results from Manning's lab further demonstrated that mTORC1 is necessary for SREBP activity (Duvel et al., 2010; Yecies et al., 2011). mTORC1 promotes hepatic lipogenesis by activating SREBP in an S6K1-dependent and S6K1-independent manner (Peterson et al., 2011; Owen et al., 2012; Caron et al., 2015; Han et al., 2015). Although the mechanism of S6K1-dependent activation of SREBP is unclear, the S6K1-independent activation of SREBP involves inhibition and phosphorylation of CRTC2 (CREB regulated transcription coactivator 2) and Lipin-1 (Peterson et al., 2011; Han et al., 2015). CRTC2, a master regulator of gluconeogenesis, competes with $\mathrm{Sec} 23 \mathrm{~A}$, a subunit of the COPII complex, to interact with Sec31A, another COPII subunit, thus disrupting SREBP1 transport from the ER to the Golgi. During feeding, mTOR is activated by insulin and/ or amino acids, and then phosphorylates CRTC2, thereby attenuating the inhibitory effect of CRTC2 on COPII-dependent SREBP1 maturation (Han et al., 2015).

mTORC1 also regulates the SREBP transcriptional network at the transcriptional level via the negative regulation of Lipin-1, a phosphatidic acid phosphatase required for glycerolipid biosynthesis (Peterson et al., 2011). When phosphorylated by mTOR, Lipin-1 resides in the cytoplasm, while the dephosphorylated Lipin-1 shuttles to the nucleus. Nuclear Lipin-1 promotes the association of SREBPs with the nuclear matrix and inhibits their ability to bind SREcontaining lipogenic genes (Peterson et al., 2011). It should be noted that mTORC1 signaling is essential, but not sufficient, to activate SREBP-dependent lipogenesis in the liver. Since mTORC1 has positive regulatory roles in lipid synthesis, it was expected that liver-specific Tsc1 null mice would develop severe hepatosteatosis. However, Tsc1 null mice were protected against age- and diet-induced hepatic lipid accumulation (Yecies et al., 2011). It is possible that the constitutively active mTORC1 negatively feeds back to AKT, thereby enhancing the expression of Insig2a, a negative regulator of SREBPs in the liver, and finally inhibiting the processing of SREBPs (Yecies et al., 2011).

As discussed above, mTORC1 enhances lipogenesis via the positive regulation of SREBPs. It remains unclear whether mTORC1 affects other transcriptional regulators of lipogenic genes. Since mTORC1 is over-activated due to the enhanced levels of branched chain amino acids in obese models (Um et al., 2004; Khamzina et al., 2005; Han et al., 2015), these recent insights into the regulation of lipogenesis by mTORC1 provide us with a better picture to understand the selective insulin resistance that underlies the enhanced lipogenesis and gluconeogenesis in obese animals. 


\section{MTORC1 INHIBITS LIPOPHAGY}

mTORC1 inhibits lipophagy mainly through the inhibition of autophagy and lysosome biogenesis (Fig. 1C). mTORC1 inhibits the autophagy-initiating UNC-51-like autophagy activating kinase (ULK) complex by phosphorylating complex components including autophagy-related gene 13 (ATG13) and ULK1/2. mTORC1 phosphorylates ULK1 and prevents the phosphorylation of ULK1 by AMPK. Moreover, mTORC1 phosphorylates ATG14L, a component of the VPS34 complex, thereby inhibiting the kinase activity of VPS34 and blocking autophagosome formation (Ganley et al., 2009; Hosokawa et al., 2009; Jung et al., 2009; Kim et al., 2011; Yuan et al., 2013; Shimobayashi and Hall, 2014; Kim and Guan, 2015).

The lysosome is a central organelle for energy metabolism and for nutrient sensing and recycling in response to starvation or nutritional stress (Xu and Ren, 2015). mTORC1 also inhibits lysosome biogenesis at the transcriptional level by the direct phosphorylation of TFEB. TFEB, a member of the MiTF/TFE (microphthalmia-associated transcription factor) family of transcription factors that includes MITF, TFE3 (transcription factor binding to IGHM enhancer 3), TFEB and TFEC, controls the expression of an array of genes involved in lysosome biogenesis and autophagy (Settembre et al., 2013b; Raben and Puertollano, 2016).

Under fed conditions, TFEB is phosphorylated by mTOR at multiple serine residues and sequestered in the cytoplasm by binding to 14-3-3 (Pena-Llopis et al., 2011; Martina et al., 2012; Roczniak-Ferguson et al., 2012; Settembre et al., 2012). In contrast, starvation induces calcium release from lysosomes through MCOLN1 (Mucolipin 1), further activating the calcium-dependent protein phosphatase 2B (PP2B/calcineurin), and thereby promoting TFEB dephosphorylation (Medina et al., 2015). In addition, FGF21, a fasting-induced hormone, promotes lipid oxidation and ketogenesis, and enhances PP2A-dependent dephosphorylation of TFEB (Chen et al., 2017). Dephosphorylated TFEB shuttles to the nucleus and directly binds to a 10-base pair motif known as a CLEAR (coordinated lysosomal expression and regulation) element, which is enriched in the promoter of numerous autophagic and lysosomal genes (Sardiello et al., 2009; Settembre et al., 2011; Settembre et al., 2013b). By activating the transcription of these genes, TFEB promotes autophagy and lysosome biogenesis. Furthermore, TFEB has been shown to promote lipid oxidation by upregulating the expression of PPAR $\alpha$ and PPARy coactivator $1 \alpha$ (PGC1a) (Settembre et al., 2013a), which are master regulators of lipid oxidation and mitochondrial biogenesis (Handschin and Spiegelman, 2006; Fan and Evans, 2015). HLH-30, an orthologue of TFEB in C. elegans has a similar effect on lipid metabolism (O'Rourke and Ruvkun, 2013), indicating that the roles of TFEB in lipid metabolism are conserved. Therefore, TFEB orchestrates lipophagy by coordinating lysosome biogenesis, autophagy, lipid oxidation, and mitochondrial function.
TFE3, another member of the MiTF/TFE family, is also phosphorylated by mTORC 1 and regulates autophagy and lysosome biogenesis in starved cells by binding to the CLEAR elements of autophagic and lysosomal genes (Martina et al., 2014; Raben and Puertollano, 2016). Interestingly, ZNF306 (ZKSCAN3), a transcriptional repressor of zinc finger transcription factors, is phosphorylated by mTORC1 and stays in the nucleus to inhibit the expression of autophagic and lysosomal genes in fed cells (Chauhan et al., 2013).

Interestingly, mTORC1 is inactivated during autophagy initiation and is then reactivated, probably by the increased amino acid levels that are generated by lysosomal degradation after long periods of starvation. The reactivated mTORC1 is important for lysosomal reformation (Yu et al., 2010). Also, lysosomal positioning is critical for the kinase activity of mTORC1 (Korolchuk et al., 2011). The cooperation of $\mathrm{mTORC} 1$ with the regulators of the autophagic-lysosomal pathway ensures an efficient autophagy flux in response to different environmental cues. Defective functioning of the autophagic-lysosomal pathway, dysregulated mTORC1 signaling, and impaired lipid metabolism in the liver affect each other and may further exacerbate vulnerable lipid homeostasis and insulin sensitivity in obesity (Um et al., 2004; Khamzina et al., 2005; Yang et al., 2010; Samuel and Shulman, 2012; Han et al., 2015; Martinez-Lopez and Singh, 2015).

\section{CONCLUSIONS}

The identification of novel regulators has further strengthened our knowledge of the basic layout of mTORC1 signaling and its central role in lipid metabolism by promoting lipogenesis and inhibiting lipophagy in the liver. Even though rapamycin has been shown to increase lifespan and to protect against cancer, side effects such as dyslipidemia may limit its clinical usefulness. Therefore, identifying bona fide mTOR substrates and their molecular roles in lipid metabolism is a promising approach to generate new compounds to target these mechanisms in the future.

\section{ACKNOWLEDGEMENTS}

This work was supported by grants from National Natural Science Foundation of China (Grant Nos. 31500956, 31625014, 31471127, 31621063 , and 31322027) and National Key Research Program of China (2016YFC1304803). We apologize to those researchers whose important work could not be cited due to space restrictions.

\section{ABBREVIATIONS}

ATG13, autophagy related gene 13; CRTC2, CREB-regulated transcription coactivator 2; DEPTOR, Dishevelled, Egl-10, and Pleckstrin (DEP) domain-containing mTOR-interacting protein; mLST8, mammalian lethal with Sec13 protein 8; mSIN1, mammalian stress-activated protein kinase-interacting protein; mTOR, mechanistic target of rapamycin; mTORC1/mTORC2, mTOR complex 1/2; $\mathrm{PP} 2 \mathrm{~A} / 2 \mathrm{~B}$, protein phosphatase $2 \mathrm{~A} / 2 \mathrm{~B}$; PRAS40, proline-rich AKT 
substrate $40 \mathrm{kDa}$; PROTOR1/2, protein observed with RICTOR-1 and -2; RAPTOR, regulatory-associated protein of mTOR; RICTOR, rapamycin-insensitive companion of $\mathrm{mTOR}$; S6K1, ribosomal protein S6 kinase 1; SREBP, sterol response element-binding protein; TFEB, transcription factor EB; ULK1, UNC-51 like autophagy activating kinase; VPS34, vacuolar protein sorting 34.

\section{COMPLIANCE WITH ETHICS GUIDELINES}

Jinbo Han and Yiguo Wang declare that they have no conflict of interest. This article does not contain any studies with human or animal subjects performed by the any of the authors.

\section{OPEN ACCESS}

This article is distributed under the terms of the Creative Commons Attribution 4.0 International License (http://creativecommons.org/ licenses/by/4.0/), which permits unrestricted use, distribution, and reproduction in any medium, provided you give appropriate credit to the original author(s) and the source, provide a link to the Creative Commons license, and indicate if changes were made.

\section{REFERENCES}

Brown EJ, Albers MW, Shin TB, Ichikawa K, Keith CT, Lane WS, Schreiber SL (1994) A mammalian protein targeted by G1arresting rapamycin-receptor complex. Nature 369:756-758

Cafferkey R, Young PR, McLaughlin MM, Bergsma DJ, Koltin Y, Sathe GM, Faucette L, Eng WK, Johnson RK, Livi GP (1993) Dominant missense mutations in a novel yeast protein related to mammalian phosphatidylinositol 3-kinase and VPS34 abrogate rapamycin cytotoxicity. Mol Cell Biol 13:6012-6023

Caron A, Richard D, Laplante M (2015) The roles of mTOR complexes in lipid metabolism. Annu Rev Nutr 35:321-348

Chauhan S, Goodwin JG, Chauhan S, Manyam G, Wang J, Kamat AM, Boyd DD (2013) ZKSCAN3 is a master transcriptional repressor of autophagy. Mol Cell 50:16-28

Chen L, Wang K, Long A, Jia L, Zhang Y, Deng H, Li Y, Han J, Wang $Y$ (2017) Fasting-induced hormonal regulation of lysosomal function. Cell Res. doi:10.1038/cr.2017.45

Cornu M, Albert V, Hall MN (2013) mTOR in aging, metabolism, and cancer. Curr Opin Genet Dev 23:53-62

Duvel K, Yecies JL, Menon S, Raman P, Lipovsky Al, Souza AL, Triantafellow E, Ma Q, Gorski R, Cleaver S et al (2010) Activation of a metabolic gene regulatory network downstream of mTOR complex 1. Mol Cell 39:171-183

Efeyan A, Zoncu R, Chang S, Gumper I, Snitkin H, Wolfson RL, Kirak O, Sabatini DD, Sabatini DM (2013) Regulation of mTORC1 by the Rag GTPases is necessary for neonatal autophagy and survival. Nature 493:679-683

Fan W, Evans R (2015) PPARs and ERRs: molecular mediators of mitochondrial metabolism. Curr Opin Cell Biol 33:49-54

Ferre P, Foufelle F (2007) SREBP-1c transcription factor and lipid homeostasis: clinical perspective. Horm Res 68:72-82
Ganley IG, du Lam H, Wang J, Ding X, Chen S, Jiang X (2009) ULK1.ATG13.FIP200 complex mediates mTOR signaling and is essential for autophagy. J Biol Chem 284:12297-12305

Goldstein JL, DeBose-Boyd RA, Brown MS (2006) Protein sensors for membrane sterols. Cell 124:35-46

Gwinn DM, Shackelford DB, Egan DF, Mihaylova MM, Mery A, Vasquez DS, Turk BE, Shaw RJ (2008) AMPK phosphorylation of raptor mediates a metabolic checkpoint. Mol Cell 30:214-226

Han J, Li E, Chen L, Zhang Y, Wei F, Liu J, Deng H, Wang Y (2015) The CREB coactivator CRTC2 controls hepatic lipid metabolism by regulating SREBP1. Nature 524:243-246

Handschin C, Spiegelman BM (2006) Peroxisome proliferatoractivated receptor gamma coactivator 1 coactivators, energy homeostasis, and metabolism. Endocr Rev 27:728-735

Harrington LS, Findlay GM, Gray A, Tolkacheva T, Wigfield S, Rebholz H, Barnett J, Leslie NR, Cheng S, Shepherd PR et al (2004) The TSC1-2 tumor suppressor controls insulin-PI3K signaling via regulation of IRS proteins. J Cell Biol 166:213-223

Heitman J, Movva NR, Hall MN (1991) Targets for cell cycle arrest by the immunosuppressant rapamycin in yeast. Science 253:905909

Horton JD, Goldstein JL, Brown MS (2002) SREBPs: activators of the complete program of cholesterol and fatty acid synthesis in the liver. J Clin Invest 109:1125-1131

Hosokawa N, Hara T, Kaizuka T, Kishi C, Takamura A, Miura Y, lemura S, Natsume T, Takehana K, Yamada N et al (2009) Nutrientdependent mTORC1 association with the ULK1-Atg13-FIP200 complex required for autophagy. Mol Biol Cell 20:1981-1991

Hsu PP, Kang SA, Rameseder J, Zhang Y, Ottina KA, Lim D, Peterson TR, Choi Y, Gray NS, Yaffe MB et al (2011) The mTORregulated phosphoproteome reveals a mechanism of mTORC1mediated inhibition of growth factor signaling. Science 332:13171322

Inoki K, Li Y, Zhu T, Wu J, Guan KL (2002) TSC2 is phosphorylated and inhibited by Akt and suppresses mTOR signalling. Nat Cell Biol 4:648-657

Inoki K, Li Y, Xu T, Guan KL (2003a) Rheb GTPase is a direct target of TSC2 GAP activity and regulates mTOR signaling. Genes Dev 17:1829-1834

Inoki K, Zhu T, Guan KL (2003b) TSC2 mediates cellular energy response to control cell growth and survival. Cell 115:577-590

Jung $\mathrm{CH}$, Jun CB, Ro SH, Kim YM, Otto NM, Cao J, Kundu M, Kim DH (2009) ULK-Atg13-FIP200 complexes mediate mTOR signaling to the autophagy machinery. Mol Biol Cell 20:1992-2003

Kalender A, Selvaraj A, Kim SY, Gulati P, Brule S, Viollet B, Kemp BE, Bardeesy N, Dennis P, Schlager JJ et al (2010) Metformin, independent of AMPK, inhibits mTORC1 in a rag GTPasedependent manner. Cell Metab 11:390-401

Khamzina L, Veilleux A, Bergeron S, Marette A (2005) Increased activation of the mammalian target of rapamycin pathway in liver and skeletal muscle of obese rats: possible involvement in obesity-linked insulin resistance. Endocrinology 146:1473-1481

Kim YC, Guan KL (2015) mTOR: a pharmacologic target for autophagy regulation. J Clin Invest 125:25-32

Kim E, Goraksha-Hicks P, Li L, Neufeld TP, Guan KL (2008) Regulation of TORC1 by Rag GTPases in nutrient response. Nat Cell Biol 10:935-945 
Kim J, Kundu M, Viollet B, Guan KL (2011) AMPK and mTOR regulate autophagy through direct phosphorylation of Ulk1. Nat Cell Biol 13:132-141

Korolchuk VI, Saiki S, Lichtenberg M, Siddiqi FH, Roberts EA, Imarisio S, Jahreiss L, Sarkar S, Futter M, Menzies FM et al (2011) Lysosomal positioning coordinates cellular nutrient responses. Nat Cell Biol 13:453-460

Kunz J, Henriquez R, Schneider U, Deuter-Reinhard M, Movva NR, Hall MN (1993) Target of rapamycin in yeast, TOR2, is an essential phosphatidylinositol kinase homolog required for $\mathrm{G} 1$ progression. Cell 73:585-596

Lamming DW, Sabatini DM (2013) A central role for mTOR in lipid homeostasis. Cell Metab 18:465-469

Li S, Brown MS, Goldstein JL (2010) Bifurcation of insulin signaling pathway in rat liver: mTORC1 required for stimulation of lipogenesis, but not inhibition of gluconeogenesis. Proc Natl Acad Sci U S A 107:3441-3446

Liu P, Gan W, Inuzuka H, Lazorchak AS, Gao D, Arojo O, Liu D, Wan L, Zhai B, Yu Y et al (2013) Sin1 phosphorylation impairs mTORC2 complex integrity and inhibits downstream Akt signalling to suppress tumorigenesis. Nat Cell Biol 15:13401350

Manning BD, Tee AR, Logsdon MN, Blenis J, Cantley LC (2002) Identification of the tuberous sclerosis complex-2 tumor suppressor gene product tuberin as a target of the phosphoinositide 3-kinase/akt pathway. Mol Cell 10:151-162

Martina JA, Chen Y, Gucek M, Puertollano R (2012) MTORC1 functions as a transcriptional regulator of autophagy by preventing nuclear transport of TFEB. Autophagy 8:903-914

Martina JA, Diab HI, Lishu L, Jeong AL, Patange S, Raben N, Puertollano R (2014) The nutrient-responsive transcription factor TFE3 promotes autophagy, lysosomal biogenesis, and clearance of cellular debris. Sci Signal 7(309):ra9

Martinez-Lopez N, Singh R (2015) Autophagy and lipid droplets in the liver. Annu Rev Nutr 35:215-237

Medina DL, Di Paola S, Peluso I, Armani A, De Stefani D, Venditti R, Montefusco S, Scotto-Rosato A, Prezioso C, Forrester A et al (2015) Lysosomal calcium signalling regulates autophagy through calcineurin and TFEB. Nat Cell Biol 17:288-299

Mizushima N, Komatsu M (2011) Autophagy: renovation of cells and tissues. Cell 147:728-741

O'Rourke EJ, Ruvkun G (2013) MXL-3 and HLH-30 transcriptionally link lipolysis and autophagy to nutrient availability. Nat Cell Biol 15:668-676

Owen JL, Zhang Y, Bae SH, Farooqi MS, Liang G, Hammer RE, Goldstein JL, Brown MS (2012) Insulin stimulation of SREBP-1C processing in transgenic rat hepatocytes requires p70 S6-kinase. Proc Natl Acad Sci U S A 109:16184-16189

Pena-Llopis S, Vega-Rubin-de-Celis S, Schwartz JC, Wolff NC, Tran TA, Zou L, Xie XJ, Corey DR, Brugarolas J (2011) Regulation of TFEB and V-ATPases by mTORC1. EMBO J 30:3242-3258

Peterson TR, Sengupta SS, Harris TE, Carmack AE, Kang SA, Balderas E, Guertin DA, Madden KL, Carpenter AE, Finck BN et al (2011) mTOR complex 1 regulates lipin 1 localization to control the SREBP pathway. Cell 146:408-420

Porstmann T, Santos CR, Griffiths B, Cully M, Wu M, Leevers S, Griffiths JR, Chung YL, Schulze A (2008) SREBP activity is regulated by $\mathrm{mTORC} 1$ and contributes to Akt-dependent cell growth. Cell Metab 8:224-236

Potter CJ, Pedraza LG, Xu T (2002) Akt regulates growth by directly phosphorylating Tsc2. Nat Cell Biol 4:658-665

Raben N, Puertollano R (2016) TFEB and TFE3: linking lysosomes to cellular adaptation to stress. Annu Rev Cell Dev Biol 32:255-278

Rabinowitz JD, White E (2010) Autophagy and metabolism. Science 330:1344-1348

Roczniak-Ferguson A, Petit CS, Froehlich F, Qian S, Ky J, Angarola B, Walther TC, Ferguson SM (2012) The transcription factor TFEB links mTORC1 signaling to transcriptional control of lysosome homeostasis. Sci Signal 5(228):ra42

Rui L (2014) Energy metabolism in the liver. Compr Physiol 4:177197

Sabatini DM, Erdjument-Bromage H, Lui M, Tempst P, Snyder SH (1994) RAFT1: a mammalian protein that binds to FKBP12 in a rapamycin-dependent fashion and is homologous to yeast TORs. Cell 78:35-43

Sabers CJ, Martin MM, Brunn GJ, Williams JM, Dumont FJ, Wiederrecht G, Abraham RT (1995) Isolation of a protein target of the FKBP12-rapamycin complex in mammalian cells. J Biol Chem 270:815-822

Samuel VT, Shulman GI (2012) Mechanisms for insulin resistance: common threads and missing links. Cell 148:852-871

Sancak Y, Peterson TR, Shaul YD, Lindquist RA, Thoreen CC, BarPeled L, Sabatini DM (2008) The rag GTPases bind raptor and mediate amino acid signaling to mTORC1. Science 320:14961501

Sancak Y, Bar-Peled L, Zoncu R, Markhard AL, Nada S, Sabatini DM (2010) Ragulator-Rag complex targets mTORC1 to the lysosomal surface and is necessary for its activation by amino acids. Cell 141:290-303

Sarbassov DD, Guertin DA, Ali SM, Sabatini DM (2005) Phosphorylation and regulation of Akt/PKB by the rictor-mTOR complex. Science 307:1098-1101

Sardiello M, Palmieri M, di Ronza A, Medina DL, Valenza M, Gennarino VA, Di Malta C, Donaudy F, Embrione V, Polishchuk RS et al (2009) A gene network regulating lysosomal biogenesis and function. Science 325:473-477

Saucedo LJ, Gao X, Chiarelli DA, Li L, Pan D, Edgar BA (2003) Rheb promotes cell growth as a component of the insulin/TOR signalling network. Nat Cell Biol 5:566-571

Saxton RA, Sabatini DM (2017) mTOR signaling in growth, metabolism, and disease. Cell 168:960-976

Settembre C, Di Malta C, Polito VA, Garcia Arencibia M, Vetrini F, Erdin S, Erdin SU, Huynh T, Medina D, Colella P et al (2011) TFEB links autophagy to lysosomal biogenesis. Science 332:1429-1433

Settembre C, Zoncu R, Medina DL, Vetrini F, Erdin S, Erdin S, Huynh T, Ferron M, Karsenty G, Vellard MC et al (2012) A lysosome-to-nucleus signalling mechanism senses and regulates the lysosome via mTOR and TFEB. EMBO J 31:10951108

Settembre C, De Cegli R, Mansueto G, Saha PK, Vetrini F, Visvikis O, Huynh T, Carissimo A, Palmer D, Klisch TJ et al (2013a) TFEB controls cellular lipid metabolism through a starvation-induced autoregulatory loop. Nat Cell Biol 15:647-658 
Settembre C, Fraldi A, Medina DL, Ballabio A (2013b) Signals from the lysosome: a control centre for cellular clearance and energy metabolism. Nat Rev Mol Cell Biol 14:283-296

Shah OJ, Wang Z, Hunter T (2004) Inappropriate activation of the TSC/Rheb/mTOR/S6K cassette induces IRS1/2 depletion, insulin resistance, and cell survival deficiencies. Curr Biol 14:1650-1656

Shaw RJ, Bardeesy N, Manning BD, Lopez L, Kosmatka M, DePinho RA, Cantley LC (2004) The LKB1 tumor suppressor negatively regulates mTOR signaling. Cancer Cell 6:91-99

Shimobayashi M, Hall MN (2014) Making new contacts: the mTOR network in metabolism and signalling crosstalk. Nat Rev Mol Cell Biol 15:155-162

Singh R, Kaushik S, Wang Y, Xiang Y, Novak I, Komatsu M, Tanaka K, Cuervo AM, Czaja MJ (2009) Autophagy regulates lipid metabolism. Nature 458:1131-1135

Stocker H, Radimerski T, Schindelholz B, Wittwer F, Belawat P, Daram P, Breuer S, Thomas G, Hafen E (2003) Rheb is an essential regulator of S6K in controlling cell growth in Drosophila. Nat Cell Biol 5:559-565

Tee AR, Manning BD, Roux PP, Cantley LC, Blenis J (2003) Tuberous sclerosis complex gene products, Tuberin and Hamartin, control mTOR signaling by acting as a GTPase-activating protein complex toward Rheb. Curr Biol 13:1259-1268

Um SH, Frigerio F, Watanabe M, Picard F, Joaquin M, Sticker M, Fumagalli S, Allegrini PR, Kozma SC, Auwerx J et al (2004) Absence of S6K1 protects against age- and diet-induced obesity while enhancing insulin sensitivity. Nature 431:200-205
Wang Y, Viscarra J, Kim SJ, Sul HS (2015) Transcriptional regulation of hepatic lipogenesis. Nat Rev Mol Cell Biol 16:678-689

Xu H, Ren D (2015) Lysosomal physiology. Annu Rev Physiol 77:57-80

Yang L, Li P, Fu S, Calay ES, Hotamisligil GS (2010) Defective hepatic autophagy in obesity promotes ER stress and causes insulin resistance. Cell Metab 11:467-478

Yecies JL, Zhang HH, Menon S, Liu S, Yecies D, Lipovsky Al, Gorgun C, Kwiatkowski DJ, Hotamisligil GS, Lee CH et al (2011) Akt stimulates hepatic SREBP1c and lipogenesis through parallel mTORC1-dependent and independent pathways. Cell Metab 14:21-32

Yu L, McPhee CK, Zheng L, Mardones GA, Rong Y, Peng J, Mi N, Zhao Y, Liu Z, Wan F et al (2010) Termination of autophagy and reformation of lysosomes regulated by mTOR. Nature 465:942946

Yu Y, Yoon SO, Poulogiannis G, Yang Q, Ma XM, Villen J, Kubica N, Hoffman GR, Cantley LC, Gygi SP et al (2011) Phosphoproteomic analysis identifies Grb10 as an mTORC1 substrate that negatively regulates insulin signaling. Science 332:13221326

Yuan HX, Russell RC, Guan KL (2013) Regulation of PIK3C3/ VPS34 complexes by MTOR in nutrient stress-induced autophagy. Autophagy 9:1983-1995

Zhang Y, Gao X, Saucedo LJ, Ru B, Edgar BA, Pan D (2003) Rheb is a direct target of the tuberous sclerosis tumour suppressor proteins. Nat Cell Biol 5:578-581 